\title{
EKSISTENSI KULINER DALAM ACARA TRADISI \\ DI SITUS KABUYUTAN KABUPATEN CIAMIS \\ SEBAGAI ASET WISATA BUDAYA JAWA BARAT
}

\author{
Riadi Darwis \\ Sekolah Tinggi Pariwisata Bandung \\ riadidarwis@gmail.com
}

\begin{abstract}
ABSTRAK
Situs kabuyutan Sunda di Kabupaten Ciamis jumlahnya mencapai 348 tempat. Ia merupakan peninggalan kebudayaan masyarakat Sunda kuno dari Kerajaan Galuh dan turunannya Kabuyutan dalam konteks budaya Sunda merupakan tempat yang disakralkan dan terkait dengan sistem tritangtu. Kabuyutan berfungsi sebagai pusat pembelajaran maupun ritual keagamaan bagi masyarakat maupun komunitas dari trah keturunan raja atau ratu sudah tentu terhubung dengan faktor logistik (kuliner) yang bersifat terikat dengan persyaratannya. Tujuan penelitian ini untuk memperoleh data tentang posisi, jenis, cara penyajian, waktu mengolah dan makan, peralatan yang digunakan, serta etiket makan dan penyajian kuliner setiap acara tradisi di situs kabuyutan.Metode penelitian yang digunakan adalah metode deskriptif dengan pendekatan kualitatif. Objeknya adalah delapan situs kabuyutan di Kabupaten Ciamis. Teknik pengumpulan data yang dipakai meliputi: observasi, wawancara, dan studi dokumentasi. Alat kumpul data berupa: daftar periksa, pedoman wawancara, dan alat dokumen. Teknis analisis yang dipakai adalah reduksi data, penyajian data, penarikan dan verifikasi kesimpulan. Simpulan yang diperoleh menunjukkan bahwa posisi kuliner dalam acara tradisi di situs kabuyutan dianggap penting dan berfungsi sebagai salah satu media penyampaian pesan secara tidak tertulis atas nilai-nilai filosofis ajaran leluhur masyarakatnya; jumlah inventaris kuliner situs kabuyutan mencapai 209 jenis yang terbagi atas kategori makanan utama (tumpeng dan lauk pauknya), makanan pendamping (umbi-umbian), kue hahampangaan/ eentengan, dan pelengkap (upacara adat); cara penyajian kuliner di delapan situs kabuyutan penyajiannya relatif sama baik dalam penggunaan alat, bahan baku, maupun area penyajian; waktu pengolahan dan makan kuliner di delapan situs kabuyutan pada umumnya mengacu pada kalender adat yang telah disepakati bersama dengan durasi persiapan hingga pelaksanaan berkisar 1-4 bulan; alat pembuatan, penyajian dan piranti makan kuliner di delapan situs kabuyutan sebagain masih menggunakan alat tradisional karena di dalamnya tersimpan makna filosofis leluhur untuk generasi berikutnya; etiket penyajian makananan dan makan di delapan situs kabuyutan masih senantiasa didasarkan
\end{abstract}


atas pakem yang ada karena di dalamnya masih mengandung nilai-nilai filosofis luhur masyarakat Ciamis (Galuh) untuk membentuk pribadi yang mulia.

Kata kunci : Kuliner, cara penyajian, waktu pengolahan, alat penyajian, dan etiket penyajian dan makan.

\begin{abstract}
The site of kabuyutan Sunda in Kabupaten Ciamis amounted to 348 places. It is a cultural heritage of the ancient Sundanese of Galuh Kingdom and its derivatives Kabuyutan in the context of Sundanese culture is a sacred place and associated with the tritangtu system. Kabuyutan serves as a learning center as well as religious rituals for the community and the community of the descendants of the king or queen is certainly connected to the logistics factor (culinary) that is bound to its requirements. The purpose of this research is to obtain data about position, type, way of presentation, time to process and eat, equipment used, as well as eating etiquette and culinary presentation every tradition event at kabuyutan site. The research method that the writer use is descriptive method with qualitative approach. The object is eight kabuyutan sites in Ciamis Regency. Data collection techniques used include: observation, interview, and documentation study. Data gathering tools include: checklists, interview guides, and document tools. Technical analysis used is data reduction, data presentation, withdrawal and verification conclusion. The conclusion obtained shows that the culinary position in the traditional event at the kabuyutan site is considered important and serves as one of the unwritten message delivery media over the philosophical values of the ancestral teachings of its people; the amount of culinary inventory kabuyutan site reaches 209 types which are divided into main food categories (tumpeng and side dishes), complementary food (tubers), hahampangaan / eentengan cakes, and complementary (traditional ceremonies); the way culinary presentation in eight kabuyutan presentation sites is relatively the same both in the use of tools, raw materials, and the area of presentation; the processing and culinary time at eight kabuyutan sites generally refers to customary calendars that have been agreed along with the duration of preparation up to the implementation ranging from 1-4 months; tools for making, serving and culinary ingredients in eight kabuyutan sites still use traditional tools because they are stored in the philosophical meaning of ancestors for the next generation; the etiquette of serving and eating at eight kabuyutan sites is always based on the existing standard because it still contains the noble philosophical values of the Ciamis (Galuh) community to form a noble person.
\end{abstract}

Keywords : culinary position, culinary type, presentation method, processing and feeding time, presentation and feeding device, and presentation and eating etiquette 


\section{PENDAHULUAN}

Perkembangan kuliner sebagai salah satu sektor yang berpengaruh terhadap kontribusi pembangunan ekonomi dan pariwisata tidak diragukan lagi. Pada bidang pembangunan pariwisata, kuliner menjadi segmen yang memiliki potensi sebagai pendongkrang dan penyokong kebijakan pemerintah dalam pencapaian taget 20 juta kunjungan wisatawan mancanegara dan 275 juta kunjungan wisatawan Nusantara. Sebuah keniscayaan bahwa Indonesia sebagai negara yang multietnis dan multibudaya memiliki aset yang sangat luar biasa termasuk salah satunya adalah bidang kuliner.

Berdasarkan sejumlah kajian saat ini, data jumlah kuliner (makanan maupun minuman) yang berhasil terinventarisasi telah mencapai 5.300. Dari satu jenis saja seperti halnya soto tidak kurang ada kurang lebih 100 varian (Pusat Kajian Seni Kuliner Indonesia, 2016: 11). Dari hasil penelitian Darwis (2017: 252) tentang data inventaris jumlah ragam kuliner di satu desa di Kabupaten Garut, tepatnya Desa Pakuwon, Kecamatan Cisurupan terdapat 189 jenis. Bisa kita bayangkan jika saat ini berdasarkan data statistik BPS selama periode 2003 - 2014, jumlah desa di Indonesia mencapai 62 517, dengan rerata banyaknya kuliner seperti angka perolehan desa tersebut, taksiran kasar jumlah kuliner di Indonesia bisa mencapai 11.815.713 jenis. Sebuah angka fantastis untuk sejumlah aset. Berarti masih banyak peluang yang bisa kita gali sebagai penginventarisasian warisan kuliner. https://www.bps.go.id/linkTableDinamis/view/id/907. [9 Februari 2018].

Akhir-akhir ini, tingkat kesadaran pemerintah mengenai isu ini mulai terpikirkan sehingga dengan adanya strategi pengembangan industri pariwisata yang di dalamnya ada segmen kuliner menjadi sangat strategis sebagai bagian dari percepatan pembangunan pariwisata. Prediksi badan pariwisata internasional seperti United Nations World Tourism Organization (UNWTO) menunjukkan bahwa jumlah pendapatan dari sektor pariwisata $30 \%$ berasal dari wisata berbasis kuliner. Hal ini dikuatkan dari hasil studi Boyne, Williams, and Haul (2002) dalam The 2004 Restaurant and Foodservice Market bahwa perolehan pendapatan usaha restoran $50 \%$ berasal dari para wisatawan. Begitupun dengan kajian lainnya yang menunjukkan bahwa $40 \%$ para wisatwan melakukan pembelanjaan untuk makanan dan minuman selama berwisata.

Atas dasar sejumlah fakta ilmiah di atas, penulis semakin tertantang untuk melakukan kajian lanjutan dari yang sebelumnya dihubungkan dengan sejumlah situs budaya kabuyutan masyarakat Sunda yang ada di Jawa Barat sebagai bagian dari warisan budaya. Situs kabuyutan Sunda di Provinsi Jawa Barat (diwakili Kabupaten Ciamis), merupakan bukti peninggalan kebudayaan masyarakat Sunda yang secara historis berkaitan dengan kerajaan Sunda kuno, baik kerajaan Tarumanagara, Galuh, Sunda, Kawali, maupun Pakuan Pajajaran. Situs kabuyutan merupakan tempat yang dianggap suci dan sakral karena tempat tersebut biasanya menjadi pusat kajian dan perenungan terkait dengan kepemimpinan dan spiritualitas. Oman Abdurachman dan Yustiaji memberikan batasan pula tentang kabuyutan sebagai berikut:“Kabuyutan adalah salah satu dimensi paling 
penting dalam budaya Sunda. Dimensi ini memuat kandungan nilai, di antaranya, ilmu pengetahuan dan teknologi, sejarah dan arkeologi, dan lingkungan, baik sebagai sumber daya ekonomi maupun sebagai perlindungan untuk lingkungan lainnya (dalam Sudaryat, 2015: 45-46)."

Berdasarkan posisi dan fungsi kabuyutan sebagai pusat pembelajaran maupun ritual keagamaan bagi masyarakat maupun komunitas dari trah keturunan raja atau ratu Sunda, mau tidak mau kebutuhan logistik selama "belajar" atau kegiatan ritual spiritual sudah menjadi bagian yang tidak terpisahkan untuk kurun waktu tertentu. Logistik makanan dan minuman selama "belajar" tentunya menjadi hal menarik mengingat faktor tersebut menjadi salah satu keperluan yang bersifat terikat dengan persyaratan belajar atau ritual sebagai sebuah tradisi.

Tradisi sebagai salah satu bagian dari kebudayaan sebagaimana yang dijelaskan oleh ahli di atas berasal dari kata traditium secara mendasar mengandung arti segala sesuatu yang diwarisi dari masa lalu. Sesuatu yang diwariskan tidak berarti harus diterima, dihargai, diasimilasi, atau disimpan sampai mati. Tradisi merupakan suatu gambaran sikap dan perilaku manusia yang telah berproses dalam waktu lama dan dilakukan secara turun-temurun dimulai dari para leluhur. Hal yang paling mendasar dari tradisi adalah adanya informasi yang diteruskan dari generasi ke generasi baik tertulis maupun lisan, karena tanpa adanya ini, suatu tradisi dapat punah. Selain itu, tradisi juga dapat diartikan sebagai kebiasaan bersama dalam masyarakat yang secara otomatis akan mempengaruhi aksi dan reaksi dalam kehidupan sehari-hari para anggota masyarakat tersebut (Tasik Untan, 2012: Tersedia https:/tasikuntan.wordpress.com/2012/11/30/pengertian-tradisi/ [22 Februari 2018]).

Secara etimologikata "kuliner" yang sudah terlanjur dikenal masyarakat memiliki makna khusus. Berikut penulis sampaikan sejumlah batasannya dari sejumlah sumber.

1. Webster's Third New Internastional Dictionary of The English Language

“Culinary \,kələ’nerēə, kyul- $\backslash$ adj. [L, culinarius, fr, culina kitchen + -arius -ary -more at KILN]: of relating to the kitchen or cookery ( art): suited for cooking ( herbs) (2002: 551)."

2. The Shorter Oxford English Dictionary on Historical Principles Third Edition Revised with Addenda

"Culinary (kiū'lināri), a. 1638 [ad. L, culinarius, f. culina.] 1. of or pertaining to kitchen; kitchen -. 2. of or pertaining to cookery 1651; of vegetables; fit for cooking 1796 1. A very c. Goddes 1856 a. The palate underpraved By c. Arts Cowper. C. Roots and plants Morse. Hence cu.linarily $a d v$. (rare) (1972: 436)."

3. The American Heritage Dictionary of the English Language Third Edition

“Cu.li.nar.y (kyōō'lə-něr-ē, kūl'ə- )adj. of relating to the kitchen or to cookery. . [L, culinarius, from culina kitchen.] see pek $^{\mathrm{w}}$ - in Appendix (1992: 454)." 
Berdasarkan ketiga sumber di atas disepakati bahwa kata kuliner termasuk jenis kata adjektiva (kata keterangan untuk nomina) yang berhubungan dengan dapur atau memasak. Adapun orang yang ahli di bidang memasak dalam sumber pertama dinamakan "culinarian".

Sebenarnya berdasarkan diksi yang tepat untuk menggambarkan perkembangan budaya makan dan pola komsumsi makanan adalah "gastronomi". Dalam Oxford Dictionary online disebutkan bahwa "gastronomy, n. The practice or art of choosing, cooking, and eating good food (Oxford, 2018: Tersedia: https://en.oxforddictionaries.com/ definition/gastronomy [20 Februari 2018]." Artinya, gastronomi adalah praktik atau seni memilih, memasak, dan makan makanan enak. Dalam kajian kali ini penulis menyengaja menggunakan kata "kuliner" karena secara popularitas masyarakat lebih kenal dan paham akan makna yang dimaksud. Kuliner dalam pandangan ilmu sosial termasuk salah satu bagian dari gaya hidup manusia. Sartono Kartodirjo ( Rahman, 2016: 7) menjelaskan bahwa gaya hidup dengan segala simbolnya mencerminkan status, peranan, kekuasaan, dan keterampilan para pendukung gaya hidup itu. Menurutnya anasir-anasir gaya hidup mencakup: aspek tempat tinggal, kebiasaan makan, pakaian, hiburan, kepercayaan, dan solidaritas. Perkembangan gaya hidup menurutnya tidak bisa terlepas dari aspek dinamis yang bertemali dengan konteks sosial, politik, hingga landasan ekonomi.

Dalam konteks kebudayaan, kebiasaan makan ada hubungannya dengan tingkah laku dan sikap-sikap yang dianggap pantas ketika aktivitas makan berlangsung. Peter B. Hammond (Rahman, 2016: 7) menyebutkan bahwa:

susunan kebiasaan dalam makan meliputi: apa dan bagaimana makanan yang sebaiknya dimakan (what to eat and how); kombinasi makanan yang pantas (the appropriate combination of food); cara penyajian yang pantas (the rightway to serve); waktu yang pantas untuk makan (the proper times to eat); peralataan yang tepat untuk digunakan (the correct utensils to eat); dan etiket makan dan penyajiaan yang baik ("good" table manners).

Rahman (2016: 8) menjelaskan sisi kemenarikan kebiasaan makan yaitu wacana mengenai makanan itu sendiri. Perubahan wacana itu muncul sebagai akibat dari pergeseran dalam melihat makanan sebagai persoalan kepraktisan menjadi wujud persoalan estetika yaitu suatu tampilan kompetensi sosial atau cita rasa yang dianggap tinggi (Chaney dalam Rahman, 2016: 8). Pandangan penulis sendiri tentang kebiasan makan dalam konteks upacara tradisi dalam komunitas etnik dan budaya Sunda sangat bisa jadi setelah melalui sentuhan moral, etika, estetika, dan petunjuk status sosial masyarakat Sunda sendiri.

Sejalan dengan pandangan Rahman dan Chaney menyangkut cita rasa makanan, Stephen Mennell (Rahman, 2016: 8)menyampaikan pendapatnya bahwa "Gagasan tentang 'citarasa yang diperoleh' bagaimanapun tidak jauh dari gagasan bahwa orang menyukai apa yang sudah biasa mereka alami: pengakuan atas kesukaan atau ketidaksukaan kuliner yang dikondisikan oleh pengaruh sosial tidak memperdalam pengertian kita akan 
bagaimana halus dan rumitnya pengaruh-pengaruh itu berlangsung." Menurutnya bahasan kebiasan makan dalam kaca mata ilmu-ilmu sosial saat ini tidak lepas dari pengaruh pemikiran strukturalisme para ahli antropologi, semiologi, dan sosiologi.

Adapun tujuan penelitian ini untuk menemukan informasi dan format: (1) posisi kuliner; (2) jenis kuliner ; (3) cara penyajian kuliner; (4) waktu yang pantas untuk mengolah dan makan kuliner; (5) peralatan yang digunakan untuk penyajian dan makan kuliner; dan (6) etiket makan dan penyajian kuliner yang baik setiap acara tradisi di situs kabuyutan Kabupaten Ciamis, Provinsi Jawa Barat.

\section{METODOLOGI}

Kajian yang digarap dalam kesempatan ini dirancang dengan menggunakan pendekatan kualitatif. Berdasarkan pernyataan Bungin (2013:29), pendekatan kualitatif adalah rangkaian kerja penelitian yang sasarannya terbatas, namun tingkat kedalaman datanya tanpa batas. Oleh karenanya, sebuah hasil penelitian yang berkualitas sangat ditentukan oleh tingkat kedalaman dan tingginya kadar kualitas data yang dikumpulkan atau diperoleh. Pendekatan ini penulis gunakan dalam penelitian ini karena dianggap penting untuk memperoleh kedalaman data mengenai eksistensi kuliner dalam acara tradisi di situs kabuyutan Kabupaten Ciamis, Provinsi Jawa Barat.

Adapun metode penelitian yang penulis pakai dalam penelitian ini berupa metode deskriptif. Metode ini penulis gunakan untuk memperoleh deskripsi atau gambaran tentang eksistensi kuliner dalam acara tradisi di situs kabuyutan. Penelitian ini berlokasi di delapan situs kabuyutan yang berada di Kabupaten Ciamis, Provinsi Jawa Barat. Objek dalam penelitian ini yaitu keberadaan dan peran kuliner dalam acara tradisi yang diselenggarakan di situs tersebut.

Subjek penelitian dalam penelitian ini adalah penjelasan populasi dan sampel berdasarkan perspektif penelitian kualitatif. Istilah populasi dalam penelitian kualitatif menurut Spradley dalam Ibrahim tidak digunakan (2015:66). Menurutnya hal tersebut lebih cenderung dinamakan "social situation" atau situasi sosial yang di dalamnya terdiri atas tiga elemen yaitu tempat (place), pelaku (actors), dan aktivitas (activity).

1) Tempat (place) dalam penelitian ini adalah situs kabuyutan yang terdapat di Kabupaten Ciamis, Provinsi Jawa Barat.

2) Pelaku (actors) dalam penelitian ini adalah pelaku adat dan tradisi di situs kabuyutan yang terdapat di Kabupaten Ciamis, Provinsi Jawa Barat yang dijadikan sebagai informan dan dianggap mengetahui keberadaan kuliner dalam lingkup acara tradisi.

3) Aktivitas (activity) dalam penelitian ini adalah segala aktivitas berupa acara tradisi yang melibatkan unsur kuliner di dalamnya dan diselenggarakan di kawasan situs kabuyutan yang terdapat di Kabupaten Ciamis, Provinsi Jawa Barat. dengan melibatkan unsur kuliner. 
Teknik-teknik pengumpulan data yang penulis pakai dalam penelitian ini meliputi observasi lapangan, dokumentasi, dan wawancara. Observasi lapangan yaitu mengunjungi delapan situs kabuyutan: (1) Situs Jambansari, (2) Situs Astana Gede Kawali, (3) Situs Karangkamulyan, (4) Situs Karamat Salawe, (5) Situs Karamat Gandoang, (6) Situs Gunung Susuru, (7) Situs Kampung Adat Kuta, dan (8) Situs Panjalu. Observasi lainnya dilakukan pula ke sejumlah pasar (Pasar Ciamis, Pasar Kawali, dan Pasar Krangkamulyan). Dokumentasi adalah mengumpulkan dokumen baik yang berbentuk tulisan, gambar (foto), maupun karya lainnya. Dalam penelitian ini, wawancara dilakukan dengan sejumlah tokoh masyarakat baik pengelola, penggiat kebudayaan, maupun pihak aparat untuk memberikan kejelasan dan kesesuaian terhadap data yang diperlukan dan berjumlah 21 orang. Demi kelancaran pelaksanaan penelitian yang akan dilakukan ada sejumlah alat bantu untuk mengumpulkan berbagai data hasil penelitian yang secara umum terdiri atas: (1) daftar periksa, (2) pedoman wawancara, dan (3) alat pendokumentasian.

Berkaitan dengan penganalisisan hasil penelitian, teknik analisis yang digunakan adalah teknik analisis data model interaktif atau model tahapan (flow model). Teknik analisis ini merupakan konsep Miles dan Hubberman dalam Ibrahim (2015:109) yang terdiri atas tiga kegiatan meliputi: (1) kegiatan reduksi data (data reduction), (2)penyajian data (data display), dan (3) penarikan serta pengujian kesimpulan (drawing and verifying conclusion). Hal ini tergambarkan dalam

\section{HASIL DAN PEMBAHASAN}

\section{A. Posisi Kuliner dalam Acara Tradisi di Situs Kabuyutan Ciamis, Provinsi Jawa Barat}

Berdasarkan sejumlah pendapat para narasumber yang ada di situs kabuyutan Ciamis, semua jenis makanan dan minuman memegang posisi penting dalam upacara. Jumlah jenis varian makananan dan minuman menjadi media edukasi tentang arti filosofis menjalani kehidupan bermasyarakat dan berspiritual. Terdapat unsur kepatutan dan kepatuhan terhadap pemimpin dan orang yang dihormati sesuai dengan ajaran para leluhur.

Simbolisasi jumlah persyaratan mengandung makna mendalam sesuai dengan sendi ajaran. Semisal jumlah angka tujuh terkait dengan adanya jumlah hari dalam seminggu, tujuh lapis bumi dan langit. Begitupun dengan angka sembilan yang ada di karang kamulyan menyimbolkan tentang adanya jumlah situs yang ada, jumlah para wali penyebar agama Islam, tanggal dan waktu peringatan Gong Perdamaian Dunia.

Adanya air dalam berbagai rasa mengandung pemaknaan berikut. Air menjadi unsur kehidupan yang penting bagi manusia dan alam sekitar. Air adalah media penetralisasi untuk membersihkan dan menyucikan diri. Varian rasa air yang ditempatkan dalam batok, cangkir, atau gelas adalah pembelajaran kepada manusia agar selalu ingat dalam kepala 
yang disimbolkan dengan batok bahwa hidup itu akan menghadapi berbagai kondisi seperti: kepahitan, kebahagiaan, kesejahteraan, dan keselamatan. Oleh karenanya manusia harus selalu ingat dan mendekatkan diri kepada Tuhan Yang Mahakuasa yang telah memberi berbagai nikmat.

Adanya kue cara merah dan putih maupun adanya bubur merah dan bubur putih. Unsur putih melambangkan bahwa kehadiran kita ke dunia ini diperantarakan dari adanya kesucian niat kedua orang tua kita hingga kita sebagai bakal makhluk yang dikandung dalam janin oleh Ibu (simbol segumpal darah dengan kue cara merah). Oleh karenanya kita harus senantiasa hormat dan patuh kepada kedua orang tua. Bubur merah dan putih melambangkan bahwa manusia senantiasa diuji antara nilai kebaikan dan keburukan. Ini memberi arti kita harus senantiasa bisa mempertahankan sisi kebaikan (putih) yang ada di dalam diri (di tengah wadah) meskipun di luar diri kita banyak rongrongan atau godaan (yang disimbolkan bubur merah yang mengelilinginya.

Hadirnya buah-buahan, umbi-umbian, maupun sayur-sayuran yang bermacam-macam mengandung makna berikut. Dalam menjalani kehidupan haruslah sampai bisa menghasilkan sesuatu yang bermanfaat baik untuk diri pribadi, keluarga, maupun masyarakat. Manusia harus hafal tentang cangkang dan isi artinya harus memahami hakikat siapa yang memberikan segala nikmat dan persaan yang beraneka kepada manusia. Begitupun dengan buah kelapa yang wajib untuk dihadirkan karena pohon kelapa disimbolkan pohon yang paling banyak manfaatnya mulai dari akar, batang, daun, hingga buah. Ini memberi pelajaran bahwa kita harus belajar menjadi manusia yang banyak manfaat.

Adanya aneka bunga yang wangi dan berwarna-warni memberikan makna berikut. Dalam menjalankan ibadah manusia harus bisa belajar untuk fokus dan salah satu medium untuk mencapai kekhusuan adalah dengan dihadirkannya wewangian sebagai stimulan. Wewangian dan beraneka warna memberi pemaknaan bahwa diri manusia harus bisa menjaga kewibawaan diri, harus bisa dikenang dan menyenangkan orang lain. Senantiasa tampil menarik dan terbaik.

Menyediakan seluruh makanan dan minuman kepada para tamu dan tetangga mengandung makna berikut. Pertama, manusia harus senantiasa untuk bersyukur atas semua karunia yang telah diberikan Allah swt. Manusia harus selalu ingat kepada sesama baik anggota keluarga, orang tua, maupun tetangga. Tidak boleh membedakan satu dengan yang lainnya selaku makhluk sosial yang sama di hadapaan-Nya.

Hadirnya nasi tumpeng baik yang putih maupun yang kuning berikut lauk pauknya yang ada di dalam nasi tumpeng mempunyai nilai atau makna ajaran berikut. Bentuk nasi tumpeng yang mengerucut seperti gunung dan berujung puncak manik memberikan pemaknaan bahwa ujung kehidupan kita adalah kembali menuju Dzat Yang Mahakuasa, Mahaagung (kuning) dan Mahasuci (putih). Hadirnya kita yang disimbolkan dengan telur adalah dalam rangka menjalankan ibadah dan pengabdian kepada-Nya. Manusia harus bersahaja dan jangan bersifat sombong dan takabur disimbolkan dengan tidak memperlihatkan segala kemampuan (makanan yang tersimpan di dalam nasi tumpeng). 
Perilaku seperti di atas adalah inti dari ajaran kehidupan kerajaan Galuh. Secara makna bahwa kata "galuh" berarti 'permata'. Oleh karenanyamanusia harus mampu meraih kemuliaan dengan cara banyak berpikir dan tafakur (galih). Untuk meraih kemuliaan harus ditempuh dengan perilaku yang baik atau ikhtiar yang baik yang disimbolkan dengan galah (alat untuk meraih sesuatu).

\section{B. Jenis Kuliner dalam Acara Tradisi di Situs Kabuyutan Kabupaten Ciamis, Provinsi Jawa Barat}

Berikut ini analisisan seluruh data jenis kuliner di kedelapan situs kabuyutan yang ada di Ciamis. Berdasarkan semua data yang ada secara global jenis makanan yang ada di kawasan-kawasan tersebut terbagi atas beberapa kategori yaitu kelompok makanan utama (main course) yang diwakili oleh tumpeng dan lauk-pauknya, makanan pendamping yang diwakili oleh berbagai umbi-umbian, minuman diwakili oleh berbagai jenis minuman, makanan penutup diwakili oleh buah-buahan, kue hahampangan/ eentengan, dan kelompok pelengkap yang diwakili oleh bunga rampe, parupuyan, gula batu, gula merah, tangkue, cerutu, rokok, kelapa muda, dan kemenyan. Itu semua ada dalam 209 varian menu kuliner yang terhimpun.

Tabel 1.

Jenis Kuliner Situs Kabuyutan Kabuyutan Ciamis

\begin{tabular}{|c|l|c|c|c|c|c|c|c|c|}
\hline \multirow{2}{*}{ No. } & \multirow{2}{*}{ Nama Jenis Menu } & \multicolumn{7}{|c|}{ Nama Situs Kabuyutan } \\
\hline & & SJS & SAGK & SKK & SKS & SKG & SGS & SKAK & SP \\
\hline 1. & air kopi pahit & V & & V & V & V & & V & V \\
\hline 2 & air kopi manis & V & & V & V & V & & V & V \\
\hline 3 & air kopi golondong & & & & & V & & & \\
\hline 4 & air teh pahit & V & & V & V & V & & V & V \\
\hline 5 & air teh manis & V & & V & V & V & & V & \\
\hline 6 & air susu & V & & V & & & & & \\
\hline 7 & air kelapa & V & & V & V & V & & V & \\
\hline 8 & air bunga mawar & V & & V & & & & V & V \\
\hline 9 & bajigur & & & & & & & & \\
\hline 10 & rujak pisang & V & & & & & & V & V \\
\hline 11 & rujak asem & V & & & & & & V & \\
\hline 12 & rujak salasih & V & & & & & & V & \\
\hline 13 & dawegan, & V & & & V & V & & V & \\
\hline 14 & mangga, & V & & & & & & V & \\
\hline 15 & jeruk, & V & & & & & & & \\
\hline 16 & anggur & V & & & & & & & \\
\hline 17 & apel & V & & & & & & & \\
\hline 18 & pisang raja & & & V & & V & \\
\hline
\end{tabular}




\begin{tabular}{|c|c|c|c|c|c|c|c|}
\hline 19 & kadu, & & V & & V & $\mathrm{V}$ & \\
\hline 20 & rambutan, & & $\mathrm{V}$ & & $\mathrm{V}$ & $\mathrm{V}$ & \\
\hline 21 & jeruk, & & $\mathrm{V}$ & & $\overline{\mathrm{V}}$ & $\mathrm{V}$ & \\
\hline 22 & salak, & & $\mathrm{V}$ & & $\mathrm{V}$ & $\mathrm{V}$ & \\
\hline 23 & dukuh & & $\mathrm{V}$ & & $\mathrm{V}$ & $\mathrm{V}$ & \\
\hline 24 & bencoy, & & $\mathrm{V}$ & & & $\mathrm{V}$ & \\
\hline 25 & manggu, & & $\mathrm{V}$ & & & $\mathrm{V}$ & \\
\hline 26 & pisitan, & & $\mathrm{V}$ & & & $\mathrm{V}$ & \\
\hline 27 & burahol, & & $\mathrm{V}$ & & & $\mathrm{V}$ & \\
\hline 28 & samangka, & & $\mathrm{V}$ & & & & \\
\hline 29 & melon, & & $\mathrm{V}$ & & & & \\
\hline 30 & nanas, & & $\mathrm{V}$ & & & $\mathrm{V}$ & \\
\hline 31 & sawo, & & $\mathrm{V}$ & & & & \\
\hline 32 & pisang & & $\mathrm{V}$ & & $\mathrm{V}$ & $\mathrm{V}$ & \\
\hline 33 & bakar pisang & $\mathrm{V}$ & & & & & \\
\hline 34 & $\begin{array}{l}\text { bubuy singkong gula } \\
\text { merah }\end{array}$ & V & & & & V & \\
\hline 35 & manisan tangkue, & $\mathrm{V}$ & & & $\mathrm{V}$ & $\mathrm{V}$ & \\
\hline 36 & gula batu, & $\mathrm{V}$ & & & $\mathrm{V}$ & $\mathrm{V}$ & \\
\hline 37 & tangtang angin & $\mathrm{V}$ & & & & $\mathrm{V}$ & \\
\hline 38 & kupat & $\mathrm{V}$ & & & & $\mathrm{V}$ & \\
\hline 39 & leupeut & $\mathrm{V}$ & & & & $\mathrm{V}$ & \\
\hline 40 & cuhcur alit & $\mathrm{V}$ & & & & $\mathrm{V}$ & \\
\hline 41 & cara putih & $\mathrm{V}$ & $\mathrm{V}$ & & & $\mathrm{V}$ & \\
\hline 42 & cara merah & $\mathrm{V}$ & $\mathrm{V}$ & & . & $\mathrm{V}$ & \\
\hline 43 & cerutu dan rokok & $\mathrm{V}$ & & & $\mathrm{V}$ & $\mathrm{V}$ & \\
\hline 44 & ranginang & $\mathrm{V}$ & $\mathrm{V}$ & $\mathrm{V}$ & $\mathrm{V}$ & $\mathrm{V}$ & \\
\hline 45 & saroja & $\mathrm{V}$ & & & $\mathrm{V}$ & $\mathrm{V}$ & \\
\hline 46 & bugis & & & & $\mathrm{V}$ & $\mathrm{V}$ & \\
\hline 47 & ketan & & & & $\mathrm{V}$ & $\mathrm{V}$ & \\
\hline 48 & roti & & & & $\mathrm{V}$ & & \\
\hline 49 & tengteng & $\mathrm{V}$ & & & & $\mathrm{V}$ & \\
\hline 50 & opak & $\mathrm{V}$ & & $\mathrm{V}$ & $\mathrm{V}$ & $\mathrm{V}$ & $\mathrm{V}$ \\
\hline 51 & kolontong & & & & & & \\
\hline 52 & wajit takir & & & & & & $\mathrm{V}$ \\
\hline 53 & jawadah & & & & & & $\mathrm{V}$ \\
\hline 54 & kalua & & & & & & $\mathrm{V}$ \\
\hline 55 & ros & $\mathrm{V}$ & $\mathrm{V}$ & $\mathrm{V}$ & $\mathrm{V}$ & $\mathrm{V}$ & \\
\hline 56 & mawar, & $\mathrm{V}$ & $\mathrm{V}$ & $\mathrm{V}$ & $\mathrm{V}$ & $\mathrm{V}$ & \\
\hline 57 & melati, & $\mathrm{V}$ & $\mathrm{V}$ & $\mathrm{V}$ & $\mathrm{V}$ & $\mathrm{V}$ & \\
\hline 58 & cempaka, & $\mathrm{V}$ & $\mathrm{V}$ & $\mathrm{V}$ & $\mathrm{V}$ & $\mathrm{V}$ & \\
\hline
\end{tabular}




\begin{tabular}{|c|c|c|c|c|c|c|c|c|c|}
\hline 59 & kenanga, & $\mathrm{V}$ & & $\mathrm{V}$ & $\mathrm{V}$ & $\mathrm{V}$ & & $\mathrm{V}$ & \\
\hline 60 & gardena/ kacapiring & $\mathrm{V}$ & & $\overline{\mathrm{V}}$ & $\overline{\mathrm{V}}$ & $\overline{\mathrm{V}}$ & & & \\
\hline 61 & sedap malam & V & & $\mathrm{V}$ & $\mathrm{V}$ & $\mathrm{V}$ & & $\mathrm{V}$ & \\
\hline 62 & singkong, & $\mathrm{V}$ & & $\mathrm{V}$ & $\mathrm{V}$ & $\mathrm{V}$ & $\mathrm{V}$ & $\mathrm{V}$ & $\mathrm{V}$ \\
\hline 63 & talas & $\mathrm{V}$ & & $\mathrm{V}$ & $\mathrm{V}$ & $\mathrm{V}$ & $\mathrm{V}$ & $\mathrm{V}$ & \\
\hline 64 & ganyong/ganyol & $\mathrm{V}$ & & $\mathrm{V}$ & $\mathrm{V}$ & $\mathrm{V}$ & & $\mathrm{V}$ & \\
\hline 65 & kentang & $\mathrm{V}$ & & & & & & $\mathrm{V}$ & \\
\hline 66 & hui boled & $\mathrm{V}$ & & V & & & $\mathrm{V}$ & $\mathrm{V}$ & \\
\hline 67 & hui areuy & & & $\overline{\mathrm{V}}$ & & & & $\overline{\mathrm{V}}$ & \\
\hline 68 & hui beuti & & & $\mathrm{V}$ & & & & $\mathrm{V}$ & \\
\hline 69 & suweg & & & $\mathrm{V}$ & & $\mathrm{V}$ & & $\mathrm{V}$ & \\
\hline 70 & gandola & V & & & & & & $\mathrm{V}$ & \\
\hline 71 & tarigu & $\mathrm{V}$ & & & & $\mathrm{V}$ & & $\mathrm{V}$ & \\
\hline 72 & kentang & $\mathrm{V}$ & & & & & & $\mathrm{V}$ & \\
\hline 73 & kentang bulu & $\mathrm{V}$ & & & & & & $\mathrm{V}$ & \\
\hline 74 & suuk & $\overline{\mathrm{V}}$ & & & $\mathrm{V}$ & $\mathrm{V}$ & $\mathrm{V}$ & $\mathrm{V}$ & \\
\hline 75 & suweg & $\mathrm{V}$ & & & & $\mathrm{V}$ & & $\mathrm{V}$ & \\
\hline 76 & jagung & & & & & $\mathrm{V}$ & & $\mathrm{V}$ & \\
\hline 77 & tumpeng bodas & $\mathrm{V}$ & & & $\mathrm{V}$ & $\mathrm{V}$ & & $\mathrm{V}$ & \\
\hline 78 & timpeng koneng & $\mathrm{V}$ & $\mathrm{V}$ & & $\mathrm{V}$ & $\mathrm{V}$ & & $\mathrm{V}$ & \\
\hline 79 & bakakak & $\mathrm{V}$ & & & & $\mathrm{V}$ & & $\mathrm{V}$ & \\
\hline 80 & ayam rosul & $\mathrm{V}$ & & & & & & & \\
\hline 81 & oreg & $\mathrm{V}$ & & & & & & $\mathrm{V}$ & \\
\hline 82 & asin & $\mathrm{V}$ & & & & $\mathrm{V}$ & & $\mathrm{V}$ & \\
\hline 83 & tahu & $\mathrm{V}$ & & & & $\mathrm{V}$ & & $\mathrm{V}$ & \\
\hline 84 & tempe & $\mathrm{V}$ & & & & $\mathrm{V}$ & & $\mathrm{V}$ & \\
\hline 85 & $\begin{array}{l}\text { puncak manik (telur, } \\
\text { bawang merah, cabe } \\
\text { merah) }\end{array}$ & & V & & V & $\mathrm{V}$ & & V & \\
\hline 86 & gepukan & & $\mathrm{V}$ & & & & & & \\
\hline 87 & dongdo & & $\mathrm{V}$ & & & & & $\mathrm{V}$ & \\
\hline 88 & galendo & & $\mathrm{V}$ & & $\mathrm{V}$ & & & $\mathrm{V}$ & \\
\hline 89 & sop hayam & & $\mathrm{V}$ & & & & & & \\
\hline 90 & sop dengkul & & $\overline{\mathrm{V}}$ & & & & & & \\
\hline 91 & gule babat & & $\mathrm{V}$ & & & & & & \\
\hline 92 & tumis tempe & & $\mathrm{V}$ & & & & & $\mathrm{V}$ & \\
\hline 93 & tumis leunca & & $\mathrm{V}$ & & & & & $\mathrm{V}$ & \\
\hline 94 & acar & & $\mathrm{V}$ & & & & & $\mathrm{V}$ & \\
\hline 95 & sayur tahu & & $\mathrm{V}$ & & & & & & \\
\hline 96 & capcay & & $\mathrm{V}$ & & & & & & \\
\hline 97 & kukumbu & & $\mathrm{V}$ & & & & & $\mathrm{V}$ & \\
\hline 98 & lalab & & $\mathrm{V}$ & & & & & $\mathrm{V}$ & \\
\hline 99 & sambal & & $\mathrm{V}$ & & & & & $\mathrm{V}$ & \\
\hline
\end{tabular}




\begin{tabular}{|c|c|c|c|c|c|c|c|c|}
\hline 100 & acara gurame & $\mathrm{V}$ & & & & & & \\
\hline 101 & pais lauk & $\mathrm{V}$ & & & & & $\mathrm{V}$ & \\
\hline 101 & sop & $\mathrm{V}$ & & & & & & \\
\hline 102 & kerupuk udang & $\mathrm{V}$ & & & & & & \\
\hline 103 & $\begin{array}{l}\text { sambal goreng } \\
\text { kentang }\end{array}$ & V & & & & V & $\mathrm{V}$ & \\
\hline 104 & $\begin{array}{l}\text { sambal goreng ati- } \\
\text { peuteuy }\end{array}$ & V & & & & & & \\
\hline 105 & sambal tarasi & $\mathrm{V}$ & & $\mathrm{V}$ & $\mathrm{V}$ & $\mathrm{V}$ & $\mathrm{V}$ & \\
\hline 106 & sambal goang/ dadak & $\mathrm{V}$ & & $\mathrm{V}$ & $\mathrm{V}$ & $\mathrm{V}$ & $\mathrm{V}$ & \\
\hline 107 & sate & $\mathrm{V}$ & & & & & & \\
\hline 108 & emih golosor & $\mathrm{V}$ & & & & & $\mathrm{V}$ & \\
\hline 109 & dage galendo & & $\mathrm{V}$ & & & & & \\
\hline 110 & $\begin{array}{l}\text { camai (dage daun } \\
\text { talas yang prosesnya } \\
\text { digarang) }\end{array}$ & & V & & & & & \\
\hline 111 & angeun lompong & & $\mathrm{V}$ & & & & $\mathrm{V}$ & \\
\hline 112 & oseng gedang & & $\mathrm{V}$ & & & $\mathrm{V}$ & & \\
\hline 113 & $\begin{array}{l}\text { udikan (goreng } \\
\text { ikan kecil yang } \\
\text { ukurannya di bawah } \\
\text { kelingking) }\end{array}$ & & V & & & & & \\
\hline 114 & sangu oyek (sampeu) & & $\mathrm{V}$ & & $\mathrm{V}$ & & $\mathrm{V}$ & \\
\hline 115 & gaplek & & $\mathrm{V}$ & & & & $\mathrm{V}$ & \\
\hline 116 & pais daging ayam & & $\mathrm{V}$ & & & & $\mathrm{V}$ & \\
\hline 117 & goreng tempe & & $\mathrm{V}$ & & $\mathrm{V}$ & $\mathrm{V}$ & $\mathrm{V}$ & \\
\hline 118 & goreng tahu & & $\mathrm{V}$ & & $\mathrm{V}$ & $\mathrm{V}$ & $\mathrm{V}$ & \\
\hline 119 & $\begin{array}{l}\text { teluk rajang (endog } \\
\text { siksik) }\end{array}$ & & V & & & & & \\
\hline 120 & jujut daging & & $\mathrm{V}$ & & & & & \\
\hline 121 & bawang goreng & & $\mathrm{V}$ & & & & & \\
\hline 122 & keripik gadung & & $\mathrm{V}$ & & & $\mathrm{V}$ & & \\
\hline 123 & keripik sampeu & & $\mathrm{V}$ & & $\mathrm{V}$ & $\mathrm{V}$ & $\mathrm{V}$ & \\
\hline 124 & kiripik taleus & & $\mathrm{V}$ & & & & & \\
\hline 125 & keripik pisang & & $\mathrm{V}$ & & & $\mathrm{V}$ & $\mathrm{V}$ & \\
\hline 126 & kicimpring & & & & $\mathrm{V}$ & & & \\
\hline 127 & kentang & & $\mathrm{V}$ & & & & & \\
\hline 128 & $\begin{array}{l}\text { kupat salamet juru } \\
\text { lima }\end{array}$ & & V & & & & V & \\
\hline 129 & $\begin{array}{l}\text { kupat salamet juru } \\
\text { tujuh }\end{array}$ & & V & & & & $\mathrm{V}$ & \\
\hline 130 & $\begin{array}{l}\text { tangtang angin juru } \\
\text { tilu }\end{array}$ & & V & & & & V & \\
\hline 131 & ikan bebeong, & & & $\mathrm{V}$ & & & & \\
\hline 132 & ikan lubang & & & $\mathrm{V}$ & & & & $\mathrm{V}$ \\
\hline
\end{tabular}




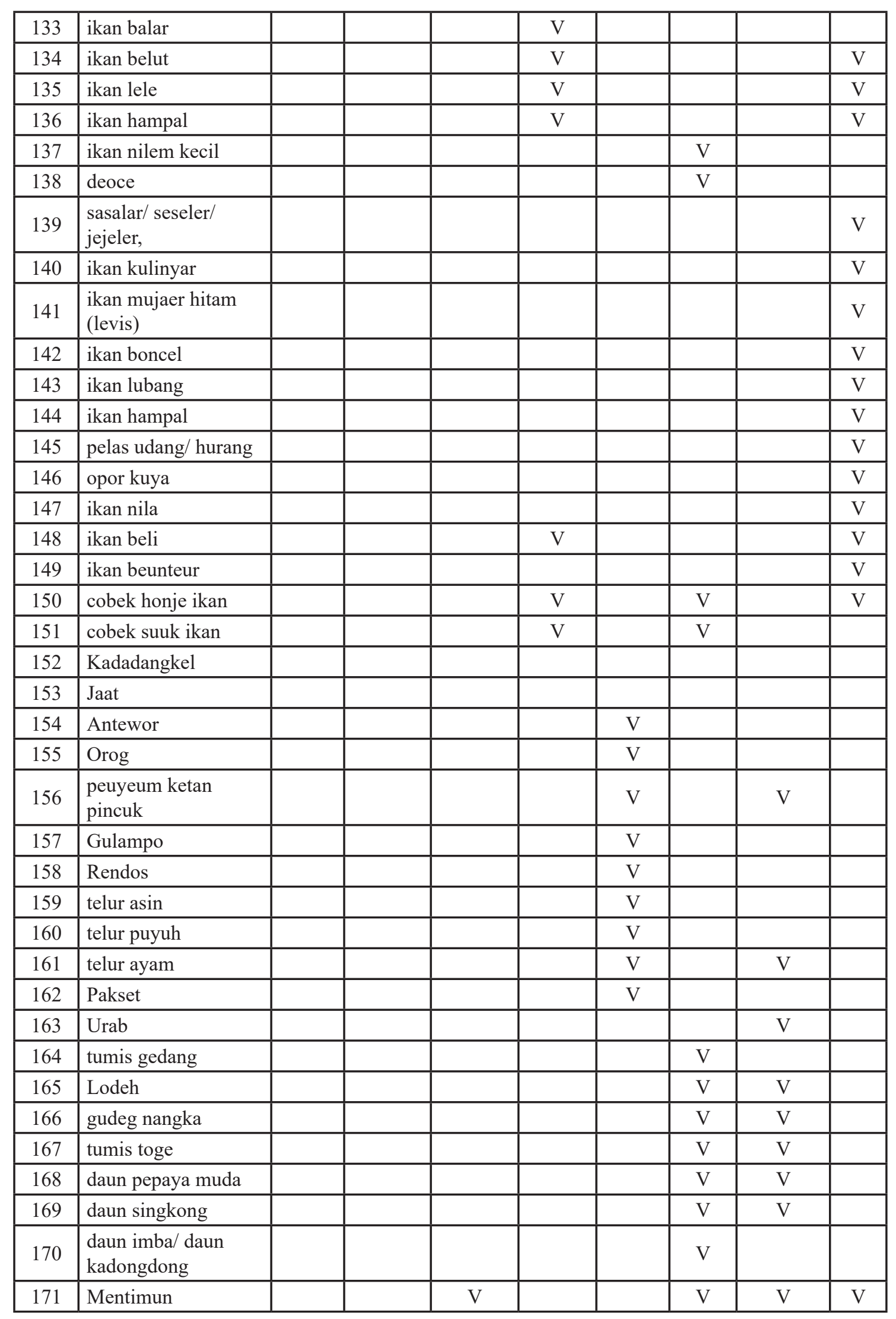




\begin{tabular}{|c|c|c|c|c|c|c|c|c|c|}
\hline 172 & Leunca & & & $\mathrm{V}$ & & & $\mathrm{V}$ & $\mathrm{V}$ & $\mathrm{V}$ \\
\hline 173 & kacang panjang & & & $\mathrm{V}$ & & & $\mathrm{V}$ & $\mathrm{V}$ & \\
\hline 174 & Terong & & & & & & $\mathrm{V}$ & $\mathrm{V}$ & \\
\hline 175 & Jengkol & & & & & & $\mathrm{V}$ & $\mathrm{V}$ & \\
\hline 176 & semur jengkol & & & & & & $\mathrm{V}$ & $\mathrm{V}$ & \\
\hline 177 & putri noong & & & & & & & $\mathrm{V}$ & \\
\hline 178 & gula merah/ kawung & $\mathrm{V}$ & $\mathrm{V}$ & $\mathrm{V}$ & $\mathrm{V}$ & $\mathrm{V}$ & $\mathrm{V}$ & $\mathrm{V}$ & $\mathrm{V}$ \\
\hline 179 & Wedang & & & & & & & $\mathrm{V}$ & \\
\hline 180 & Lemareun & & & & & & & $\mathrm{V}$ & \\
\hline 181 & sambel bakal & & & & & & & $\mathrm{V}$ & \\
\hline 182 & sayur daun kelor & & & & & & & & $\mathrm{V}$ \\
\hline 183 & telur ayam kampung & & & & & & & $\mathrm{V}$ & $\mathrm{V}$ \\
\hline 184 & Oyek & & & & & & & & $\mathrm{V}$ \\
\hline 185 & Kasungka & & & & & & & & $\mathrm{V}$ \\
\hline 186 & Bangkoe & & & & & & & & $\mathrm{V}$ \\
\hline 187 & Pining & & & $\mathrm{V}$ & & & & & $\mathrm{V}$ \\
\hline 188 & pandan wangi & & & & & & & & \\
\hline 189 & pais ikan & & & $\mathrm{V}$ & & $\mathrm{V}$ & & & $\mathrm{V}$ \\
\hline 191 & sangu rewahan & & & & $\mathrm{V}$ & & & & \\
\hline 192 & sangu sawalan & & & & $\mathrm{V}$ & & & & \\
\hline 193 & Rantangan & & & & $\mathrm{V}$ & & & & \\
\hline 194 & Awug & & & & $\mathrm{V}$ & & & $\mathrm{V}$ & \\
\hline 195 & Papais & & & & $\mathrm{V}$ & & & $\mathrm{V}$ & $\overline{\mathrm{V}}$ \\
\hline 196 & wajit biasa & & & & $\mathrm{V}$ & & & $\mathrm{V}$ & \\
\hline 197 & emi sampeu & & & & $\mathrm{V}$ & & & & \\
\hline 198 & ikan mas & & & & $\mathrm{V}$ & & & $\mathrm{V}$ & $\mathrm{V}$ \\
\hline 199 & degan/ lahang & & & & $\mathrm{V}$ & & & $\mathrm{V}$ & \\
\hline 200 & Wedang & & & & $\mathrm{V}$ & & & $\mathrm{V}$ & \\
\hline 201 & air tawar & $\mathrm{V}$ & $\mathrm{V}$ & $\mathrm{V}$ & $\mathrm{V}$ & $\mathrm{V}$ & $\mathrm{V}$ & $\mathrm{V}$ & $\mathrm{V}$ \\
\hline 202 & Ceuri & & & $\mathrm{V}$ & & $\mathrm{V}$ & & $\mathrm{V}$ & \\
\hline 203 & Burahol & & & $\mathrm{V}$ & & $\mathrm{V}$ & & $\mathrm{V}$ & \\
\hline 204 & Jambu & $\mathrm{V}$ & $\mathrm{V}$ & $\mathrm{V}$ & $\mathrm{V}$ & $\mathrm{V}$ & $\mathrm{V}$ & $\mathrm{V}$ & $\mathrm{V}$ \\
\hline 205 & Kadongdong & $\mathrm{V}$ & $\mathrm{V}$ & $\mathrm{V}$ & $\mathrm{V}$ & $\mathrm{V}$ & $\mathrm{V}$ & $\mathrm{V}$ & $\mathrm{V}$ \\
\hline 206 & nasi timbel & & & $\mathrm{V}$ & $\mathrm{V}$ & $\mathrm{V}$ & $\mathrm{V}$ & $\mathrm{V}$ & $\mathrm{V}$ \\
\hline 207 & Piritan & & & & & & & & $\mathrm{V}$ \\
\hline 208 & ikan toe & & & & & & & & $\mathrm{V}$ \\
\hline 209 & ikan corengcang & & & & & & & & $\mathrm{V}$ \\
\hline
\end{tabular}

\section{Keterangan:}

SJS = Situs Jambansari

SAGK = Situs Astana Gede kawali

SKK = Situs Karangkamulyan

SKS = Situs Karamat Salawe 


$$
\begin{array}{ll}
\text { SKG } & =\text { Situs Karamat Gandoang } \\
\text { SGS } & =\text { Situs Gunung Susuru } \\
\text { SKAK } & =\text { Situs Kampung Adat Kuta } \\
\text { SP } & =\text { Situs Panjalu }
\end{array}
$$

Dari data tersebut penulis beroleh simpulan bahwa seluruh jenis makanan maupun minuman yang ada di kedelapan situs kabuyutan, tiga kawasan utama yang memiliki banyak varian menu/ jenis makanan adalah Situs Kampung Adat Kuta (59\%), Situs Karangkamulyan (34\%), dan Situs Karamat Gandoang (33\%). Sementara tiga situs yang memiliki varian menu yang paling sedikit adalah Situs Astana Gede Kawali (14\%), Situs Gunung Susuru (16\%), dan Situs Panjalu (21\%).

Bila diperhatikan, komposisi menu yang tersaji dalam makanan di situs kabuyutan Ciamis telah mengajarkan untuk melakukan diversifikasi pangan tanpa bergantung pada penggunaan beras dan terigu sebagai bahan baku makanan sehari-hari. Hal ini sesuai dengan anjuran pihak pemerintah (Dinas Pertanian dan Ketahanan Pangan Ciamis) dalam rangka penganekaragaman pangan untuk mencapai konsumsi pangan yang berimbang, bergizi, aman, dan halal. Saat ini menurutnya angka pola pangan harapan (PHP)konsumsi masyarakat Ciamis masih kurang dan baru mencapai skor 76,7 dari angka optimal (100). Ini terbuktikan dari besaran pemanfaatan umbi-umbian hanya beroleh skor 0,9 dibandingkan dengan padi-padian yang mencapai skor 25. Begitupun untuk konsumsi kelompok pangan lain yang terbilang masih kecil seperti: buah, biji berminyak $(0,6)$, minyak dan lemak (5), gula $(2,4)$, kacang-kacangan $(4,3)$, dan pangan hewani $(16,2)$.

Terkait angka pangan hewani yang masih rendah terbukti bahwa tingkat kebutuhan dan sedian daging di Ciamis pada 2017 masih kurang untuk jenis daging sapi dan kerbau $(-57,79 \%)$ domba dan kambing $(-43,79 \%)$, ayam buras $(-53,7 \%)$, itik $(-51,87 \%)$, dan susu $(-97,11 \%)$. Sementara komoditas daging yang mampu terpenuhi adalah ayam ras pedaging dan ras petelur masing-masing mencapai 100\%, Dengan demikian pola konsumsi daging pada masyarakat harus mulai ditingkatkan (Sekretaris Dinas Peternakan dan Perikanan Ciamis). Program ini sangat penting secara politis agar masyarakat mulai menyadari betapa perlunya kita mengurangi angka impor bahan pangan. Kedua pejabat dinas terkait sependapat agar kita kembali ke konsep kearifan lokal dalam rangkamenyelamatkan keseimbangan ekosistem sekaligus memberikan keamanan dan keselamatan lingkungan yang lebih serius.

Berdasarkan potensi data di atas saat ini masyarakat di kawasan situs kabuyutan Ciamis belum sepenuhnya memanfaatkan potensi lokal pertanian untuk meningkatkan taraf kehidupan ekonomi mereka sendiri.

\section{Cara Penyajian Kuliner Setiap Acara Tradisi di Situs Kabuyutan Kabupaten Ciamis, Provinsi Jawa Barat}

Berdasarkan data terkait cara penyajian kuliner di situs kabuyutan Kabupaten Ciamis. Khusus untuk tumpeng secara keseluruhan proses tumpeng dalam penyajiannya relatif 
sama baik dalam penggunaaan alat berupa aseupan maupun bahan baku. Sementara di Situs Gunung Susuru tidak ada tumpeng dan di tempat tersebut hanya dibuatkan berupa timbel beserta lauk pauknya. Perbedaan lainya yang penulis temukan hanya tumpeng yan ada di Panjalu yang mengikuti tumpeng gaya Jawa yaitu lauk pauk tidak dimasukkan ke dalam nasi tumpeng, akan tetapi semua lauk pauknya ada di luar dan diwadahi secara terpisah (angeun daun kelor, bakakak, ikan, dll.) . Di kawasan Situs Keramat Gandoang terdapat pencampuran penyajian yaitu sebagian ada di dalam nasi tumpeng dan sisanya di luar (telur puyuh rebus yang ditata sekaligus berfungsi sebagai hiasan/ garnish). Hanya satu situs yang tidak berhasil penulis temukan rekonstruksi ada tidaknya tumpeng dalam acara tradisi yaitu di Situs Astana Gede Kawali.

Selanjutnya untuk berbagai sesajen masing-masing diwadahi dalam wadah terpisah sesuai jenisnya. Untuk jenis minuman rerata menggunakan gelas atau cangkir yang diwadahi dengan baki bundar atau persegi bahkan ada pula yang pakai cecempeh. Begitupun untuk bunga rampe, rokok-cerutu dan parupuyan sebagai pelengkap biasanya diwadahi tersendiri. Begitupun untuk umbi-umbian masing-masing diwadahi.

Keseluruhan sajian kuliner biasanya ditempatkan di ruangan/ area tertentu dan tidak seluruhnya di bawa ke dalam area inti situs (makam). Hal ini bisa kita lihat dalam kasus di Situs Karamat Jambansari, Situs Gandoang, Situs Karamat Salawe, Situs Karangkamulyan, Situs Gunung Susuru, dan Situs Panjalu. Dari sekian banyak situs hanya Situs Karangkamulyan yang dalam penyajiannya terbilang sangaat artistik karena mereka memiliki konsep semua bahan sajian hingga peralatan dan dekorasi semuanya berbahan bambu.

Sajian ditempatkan di tengah area atau ruangan yang dialasi karpet atau samak dan dikelilingi para peserta acara tradisi sambil duduk untuk menjalani doa bersama yang tujuannya agar beroleh keberkahan pada makanan yang yang tersaji.

\section{Waktu Pengolahan dan Makan Kuliner Setiap Acara Tradisi di Situs Kabuyutan Kabupaten Ciamis, Provinsi Jawa Barat}

Berdasarkan seluruh data lapangan tentang waktu pengolahan dan makan kuliner di kedelapan situs kabuyutan pada umumnya ditentukan sesuai dengan kalender adat. Lamanya waktu persiapan dan pengolahan makanan, serta acara makannya ditentukan sesuai dengan susunan acara yang telah disepakati bersama antara panitia dan seluruh warga masyarakat yang terlibat. Pada umumnya untuk acara-acara sakral yang bersifat masal seperti di bulan Mulud, mereka sudah bermusyawarah terlebih dahulu dan berkoordinasi dengan berbagai pihak terkait. Rentang waktu persiapan ada yang sudah diawali 1-2 bulan sebelumnya mengingat ada prosesi yang cukup panjang seperti yang terjadi di Situs Panjalu. Perayaan acara tradisi di beberapa situs ada hubungannya dengan penetapan acara pajang jimat di Cirebon karena ada hubungannya dengan para sesepuh di situs kabuyutan sebagai keturunan dari Kesultanan Cirebon. 
Berbeda halnya dengan di Situs Karangkamulyan, persiapan bisa memakan waktu lebih dari dua bulan mengingat acara tradisi di sini melibatkan tidak hanya orang internal sekitar kawasan, tetapi sudah mencapai tingkat nasional bahkan internasional. Di sini ada unsur perwakilan dari para kasepuhan Nusantara dan perwakilan dari berbagaai negara sahabat.

Dari kedelapan situs kabuyutan yang relatif paling sedikit waktu persiapan pernyajian adalah Situs Gunung Susuru. Di situs ini tidak terlalu banyak persiapan yang sangat mendetail. Mengingat prosesi sangat singkat. Di sini penulis tidak menemukan adanya persyaratan adat seperti tumpeng dan perlengkapan lainnya.

\section{E. Peralatan Penyajian dan MakanKuliner Setiap Acara Tradisi di Situs Kabuyutan Kabupaten Ciamis, Provinsi Jawa Barat}

Berdasarkan seluruh data terkait dengan alat penyajian berbagai jenis makanan dan minuman dalam acara tradisi di delapan situs kabuyutan Ciamis, penulis beroleh fakta bahwa alat pembuatan, penyajian dan piranti makan kuliner terdiri atas barang berbahan alami, tradisional, dan campuran modern. Untuk alat tumpeng biasanya kukusan dan alas tumpeng (nyiru/ cecempeh) terbuat dari anyaman yang dialasi dengan daun pisang manggala. Untuk berbagai makanan sesajen berupa minuman biasanya zaman dahulu dari batok sekarang dengan cangkir atau gelas. Umbi-umbian biasanya diwadahi dengan takir dari daun pisang atau menggunakan piring ataupun mangkok sesuai kemampuan. Sejajian lainnya seperti rampe disatukan dalam wadah yang sudah dicampur air. Piranti makan untuk kalangan berada langsung dengan piring dari keramik/ gelas. Untuk saat ini karena adanya perkembangan terkadang diganti dengan piring plastik/ styrofoam/ atau piring nyere beralas kertas-plastik. Pengaruh teknologi dan gaya hidup sajian air minum untuk para tamu sudah dalam bentuk air minum gelas atau botol kemasan.

Situs kabuyutan yang paling konsisten dalam mempertahan dan menerapkan nilai kearifan lokal dalam alat penyajian dan makan makanan/ kuliner adalah Situs Kampung adat Kuta dan Situs Karang kamulyan. Di situs inilah (Karangkamulyan) panitia mencoba berkreasi melakukan prosesi dengan konsep yang benar-banar matang. Semua berbahan alami termasuk wadah untuk minuman pun dari bahan alami.

\section{F. Etiket Penyajian dan MakanKuliner Setiap Acara Tradisi di Situs Kabuyutan Kabupaten Ciamis, Provinsi Jawa Barat}

Dalam bagian ini, berdasarkan sejumlah data etiket penyajian makanan dan makan dalam setiap acara tradisi di kedelapan situs kabuyutan Kabupaten Ciamis. Penulis beroleh suatu fata bahwa secara umum bahwa etiket yang dijalankan oleh masyarakat dalam penyajian makanan senantiasa didasarkan atas pakem yang ada di sana. Para pengurus atau pengelola situs termasuk kuncen dan para tokoh lainnya berupaya untuk memenuhi 
semua persyaratan yang telah ditentukan adat baik seperti jumlah jenis makanan-minuman (7-9 jenis), tidak memulai makan sebelum didoakan dan dipersilakan oleh pemilik hajat/ panitia, mempersilakan orang yang dihormati termasuk kaum lelaki terlebih dahulu untuk memulai menyantap makanan-minuman, posisi makan-minum duduk melingkung dan sejajar, orang yang dituakan biasanya akan membantu membagikan makanan.

Bila kita berkaca pada apa yang dilaksanakan masyarakat adat di kedelaapan situs, kita bisa memperoleh hikmah bahwa: ajaran kerajaan Galuh yang diwariskan kepada penerusnya berisi adanya beberapa prinsip seperti: saling menghormati kepada yang lebih tua, menyangi kepada yang lebih muda, kesopansatuntan dalam berperilaku, berjiwa egaliter (tidak adanya golongan yang kuat atau yang lemah, berpangkat atau tidak berpangkat) karena pada prinsipnya manusia di hadapan Tuhan Yang Mahakuasa adalah sama selaku makhluk yang mengabdi dan berbakti, hidup sederhana dan tidak berlebihan/ serakah, bersabar, bersyukur, dan rendah hati. Ini merupakan bentuk penerapan yang sesungguhnya ajaran dari kepercayaan yang selama ini diyakini baik Islam atau dari "kegaluhan". Harapannya dengan terus mempertahan perilaku adat seperti ini pada dasarnya kita sedang menjaga kesimbangan alam atau harmonisasi manusia dengan lingkungannya

\section{SIMPULAN}

Berdasarkan hasil analisis terhadap sejumlah data dapat ditarik sejumlah simpulan berikut. Posisi kuliner dalam acara radisi di situs kabuyutan Kabupaten Ciamis dianggap sebagai sesuatu yang penting dan berfungsi sebagai salah satu media penyampaian pesan secara tidak tertulis atas sejumlah nilai-nilai filosofis didaktis spiritual ajaran leluhur yang harus dijalankan oleh para penerusnya; jumlah inventaris kuliner (makanan, minuman, dan pelengkap) kuliner situs kabuyutan mencapai 209 jenis yang terbagi atas kategori kelompok makanan utama (tumpeng dan lauk pauknya), makanan pendamping (umbi-umbian), kue hahampangaan/ eentengan, dan pelengkap (seperti perlengkapan upacara adat); cara penyajian kuliner di situs kabuyutan Kabupaten Ciamis relatif sama baik dalam penggunaan alat, bahan baku, maupun area penyajian; waktu pengolahan dan makan kuliner di situs kabuyutan pada umumnya mengacu pada kalender adat yang telah disepakati bersama dengan durasi persiapan hingga pelaksanaan berkisar 1-4 bulan; alat pembuatan, penyajian dan piranti makan kuliner di delapan situs kabuyutan Kabupaten Ciamis sebagian sudah terpengaruh teknologi modern meskipun sebagian lagi tetap menggunakan alat tradisional dan alami yang sebenarnya di dalam piranti tersebut tersimpan makna filosofis terdalam; etiket penyajian makananan dan makan di situs kabuyutan masih senantiasa didasarkan atas pakem yang ada karena di dalamnya masih tersimpan nilai-nilai filosofis luhur ajaran leluhur masyarakat Ciamis (Galuh). 


\section{DAFTAR PUSTAKA}

Alamsyah, Yuyun. (2008). Bisnis Kuliner Tradisional: Meraih Untung dari Bisnis Masakan Tradisional Kaki Lima sampai Restoran. Jakarta: Elex Media Komputindo.

BPS. (2017). Table Dinamis. (online). Tersedia: https://www.bps.go.id/linkTableDinamis/ view/id/907. [9 Februari 2018].

Bungin, Burhan. 2013. Penelitian Kualitatif: Komunikasi, Ekonomi, Kebijakan Publik, dan Ilmu Sosial Lainnya. Jakarta: Kencana Prenada Media Group.

Darwis, Riadi. (2017). Inventarisasi Khazanah Kuliner Tradisional Desa Pakuwon Kecamataan Cisurupan Kabupaten Garut dalam Konteks pembangunan Kampung Wisata Halal. Tourism Scientific Journal Vol.2, No. 2 Juni 2017: 234-259.

Houghton Mifflin Company. (1992). The American Heritage Dictionary of The English Language. Third Ed.. Boston: Houghton Mifflin Company.

Ibrahim. 2015. Metode Penelitian Kualitatif. Bandung: Alfabeta

Little, William, Fowler, H. W., Coulson, J. (1972). The Shorter Oxfor English Dictionary on Historical Principles. Third ed. Revised with addenda. Oxford; The Clarendon Press.

Oxford University. (2018). Gastronomy”. Oxford Dictionarie. (online) : Tersedia: https:// en.oxforddictionaries.com/definition/gastronomy [20 Februari 2018]

Pusat Kajian Seni Kuliner Indonesia, Sekolah Tinggi Pariwisata Bandung. (2016). Profil Kuliner di Destinasi Pariwista Indonesia. Bandung: Pusat Kajian Seni Kuliner Indonesia, Sekolah Tinggi Pariwisata Bandung.

Rahman, Fadly. (2016). Rijstafel Budaya Kuliner di Indonesia Masa Kolonial 1870-1942. Jakarta: PT Gramedia Pustaka Utama.

Sudaryat, Yayat, Haji. (2015). Wawasan Kesundaan. Bandung: Jurusan Pendidikan bahasa Daerah, Fakultas Pendidikan Bahasa dan Sastra, UPI Bandung.

Tasik Untan. (2012). Pengertian Tradisi. (online): Tersedia https://tasikuntan.wordpress. com/2012/11/30/pengertian-tradisi/ [22 Februari 2018]).

Webster, Noah. (2002). Webster's Third new International Dictionary of The English Language Unabridged. Ed. Philip Babcock Gove \& Merriam Webster. Massachusetts: merriam-Webster Inc. 